Case Reports in
Gastroenterology
Case Rep Gastroenterol 2021;15:202-209

DOI: 10.1159/000511885

Published online: February 18, 2021
(C) 2021 The Author(s)

Published by S. Karger AG, Basel www.karger.com/crg

This article is licensed under the Creative Commons Attribution-NonCommercial 4.0 International License (CC BY-NC) (http://www.karger.com/Services/OpenAccessLicense). Usage and distribution for commercial purposes requires written permission.

\title{
Disappearance of Gastric Hyperplastic Polyps after the Discontinuation of Proton Pump Inhibitor in a Patient with Liver Cirrhosis
}

\author{
Kengo Yasugi ${ }^{\mathrm{a}}$ Ken Haruma ${ }^{\mathrm{a}}$ Miwa Kawanaka $^{\mathrm{a}}$ Mitsuhiko Suehiro $^{\mathrm{a}}$ \\ Jun Nakamura ${ }^{a}$ Noriyo Urata ${ }^{a}$ Tomohiro Tanikawa $^{a}$ Takahito Oka ${ }^{a}$ \\ Yasumasa Monobe $^{b}$ Takuya Fujita $^{c}$ Hirofumi Kawamoto ${ }^{a}$ \\ aDepartment of Internal Medicine 2, Kawasaki Medical School General Medical Center,

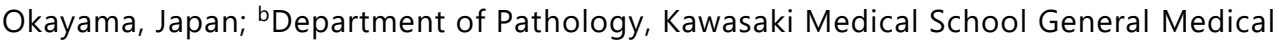 \\ Center, Okayama, Japan; ${ }^{C}$ Fujita Hospital, Okayama, Japan
}

\section{Keywords}

Gastric hyperplastic polyp · Proton pump inhibitor · Hypergastrinemia

\begin{abstract}
Here, we report on a rare case of gastric hyperplastic polyps which disappeared after the discontinuation of proton pump inhibitor (PPI). The patient was an 83-year-old woman with liver cirrhosis and portal hypertension, along with gastroesophageal reflux disease treated by PPI. An initial upper gastrointestinal endoscopy showed unique polypoid lesions in the greater curvature of the stomach. Biopsy specimens of the lesions were diagnosed as hyperplastic polyps and she was followed. One year later, a second endoscopy showed that the lesions had increased in number and size, and an endoscopic mucosal resection (EMR) was performed for the main polyps. The resected specimens indicated a proliferation of foveolar epithelium cells with an increase of capillary ectasia and parietal cell hyperplasia, which was thought to be induced by hypergastrinemia from the PPI. Three months after the EMR, she was admitted because of bleeding from the remaining polyps along with an increase in new polyps. After
\end{abstract}

\begin{tabular}{ll}
\hline & Kengo Yasugi \\
Department of Internal Medicine 2 \\
Kawasaki Medical School General Medical Center \\
2-6-1 Nakasange, Kita-ku, Okayama 700-8505 (Japan) \\
ppurOjyn@s.okayama-u.ac.jp
\end{tabular}




\section{Case Reports in Gastroenterology}

Case Rep Gastroenterol 2021;15:202-209 DOI: $10.1159 / 000511885$

(c) 20217

www.karger.com/crg

Yasugi et al.: Disappearance of Gastric Hyperplastic Polyps after the Discontinuation of Proton Pump Inhibitor in a Patient with Liver Cirrhosis

conservative treatment, PPI was stopped and rebamipide was used. One year and 6 months later, an endoscopy showed the complete disappearance of all gastric polyps.

\author{
(C) 2021 The Author(s) \\ Published by S. Karger AG, Basel
}

\title{
Introduction
}

The pathogenesis of gastric hyperplastic polyps is still unknown, but it is suggested that the exaggerated repair of mucosal damage, antral hypercontraction, and hypergastrinemia may play a role in the development of polyps. In general, gastric hyperplastic polyps develop from the atrophic gastric mucosa with inflammation induced by Helicobacter pylori (HP) infection [1] or autoimmune gastritis [2]. Moreover, several recent studies have reported that the long-term use of proton pump inhibitor (PPI) may cause not only fundic gland polyps [3, 4] but also hyperplastic polyps through hypergastrinemia [5]. The clinical significance of gastric hyperplastic polyps is whether they have malignant potential and cause anemia or not [6].

Although large or hemorrhagic gastric hyperplastic polyps can be removed endoscopically, endoscopic therapy is not a fundamental treatment for gastric hyperplastic polyps because the cause of the polyps has not been eliminated. Outside of endoscopic therapy, several recent studies have demonstrated that a regression or disappearance of gastric hyperplastic polyps is found after HP eradication therapy and/or the discontinuation of PPI [7-9].

Here, we report on a rare case of gastric hyperplastic polyps and show the unique endoscopic and pathological findings in which the gastric polyps disappeared naturally after the discontinuation of PPI in a patient with liver cirrhosis and portal hypertension.

\section{Case Presentation}

An 83-year-old woman had been treated for liver cirrhosis due to nonalcoholic steatohepatitis (NASH) and autoimmune hepatitis (AIH), with essential hypertension and gastro-esophageal reflux (GERD) at our hospital and at another outside hospital. In March 2014, an initial upper gastrointestinal endoscopy (UGE) showed multiple reddish polypoid lesions in the greater curvature of the stomach. The endoscopic finding of main polyps was unique, and a part of the mucosal folds of the greater curvature was swollen like a sausage, with a reddish surface. A red ridge on the fold beside the main lesion was also recognized. Two consecutive raised lesions on the fold beside the main lesion were also recognized. In addition, a broadbased reddish polypoid lesion was observed on the anterior wall side next to the two lesions, with a clot adhering to part of it. In addition, two small fundic gland polyps were noted (Fig. 1a).

Biopsy specimens of the lesion indicated hyperplasia of the foveolar epithelium and was diagnosed as gastric hyperplastic polyps (Fig. 1b). We suspected that those hyperplastic polyps were associated with PPI because no atrophic change was found in the stomach as a whole, all HP tests (Ig G antibody, rapid urease test, and urea breath test) were negative, and she had a long-term history of PPI use (rabeprazole $10 \mathrm{mg} /$ day). Her fasting serum gastrin level was $776 \mathrm{pg} / \mathrm{dL}$ (normal range: $50-150 \mathrm{pg} / \mathrm{dL}$ ).

One year later, she was diagnosed with pneumonia and admitted to our hospital. At that time, she had an additional diagnosis of autoimmune hemolytic anemia $(\mathrm{Hb}, 8.0 \mathrm{~g} / \mathrm{dL})$. More

\section{Karger'=}




\section{Case Reports in Gastroenterology}

Case Rep Gastroenterol 2021;15:202-209

DOI: 10.1159/000511885

www.karger.com/crg

Yasugi et al.: Disappearance of Gastric Hyperplastic Polyps after the Discontinuation of Proton Pump Inhibitor in a Patient with Liver Cirrhosis

than 2 years after that, she was admitted to our hospital with appetite loss, dizziness, and severe anemia $(\mathrm{Hb}, 5.0 \mathrm{~g} / \mathrm{dL})$. A UGE indicated multiple gastric polyps with a granular surface and natural bleeding in the curvature, the number and size of the polyps had increased compared to previous exams. In addition, new adjacent polypoid lesions were found in the greater curvature of the antrum (Fig. 2a).

An EMR was performed on the main gastric polyps and she was followed. Pathological findings of the resected polyps showed the crypt hyperplasia with an edematous lamina propria containing prominent ectasia in the vessels of the surface epithelium (Fig. 2b). In addition, there was cystic dilation of the fundic glands and a remarkable hyperplasia of the parietal cells deep in the hyperplastic polyps (Fig. 2c).

Three months after the EMR, she was admitted with hematemesis, and an emergency endoscopy revealed bleeding from the remaining gastric polyps and also from renewed polyps (Fig. 3a, b). After conservative treatment, the PPI rabeprazole (10 mg/day) was stopped and the mucoprotective agent rebamipide (300 $\mathrm{mg}$ /day) was started. She was followed at another outside hospital and her anemia was stable $(\mathrm{Hb}, 7.0 \sim 9.0 \mathrm{~g} / \mathrm{dL})$ for the next 1 year and 6 months.

She was re-admitted due to uncontrolled ascites and hepatic encephalopathy from cirrhosis. A UGE showed a post-EMR scar in the middle of the corpus and all polyps in the antrum and the lower part of the corpus had completely disappeared (Fig. 3c, d). She was treated for liver failure but died of progression of the disease 28 days after admission.

\section{Discussion/Conclusion}

Here, we reported on a rare case of gastric hyperplastic polyps with unique endoscopic and pathological findings which disappeared completely after the discontinuation of PPI. Furthermore, it was possible to stop the refractory anemia which was thought to be caused by the bleeding from the gastric polyps.

The gastric polyps in this case showed unique endoscopic findings of a sausage-like swelling of parts of the mucosal folds and broad-based reddish polyps with a relatively smooth surface. The sub-pedunculated and pedunculated dome-shaped forms were different from other more common gastric hyperplastic polyps.

Gastric hyperplastic polyps in patients with portal hypertension are known as portal hypertensive polyps or portal hypertension associated polyps. Published endoscopic findings of portal hypertensive polyps show them to be reddish, slender, with a tendency for tandem lesions with an earthworm-like swelling on the surface [10]. In general, the most common locations are in the antrum or the greater curvature; however, they are also found in the lower corpus [11]. One specific pathological finding of portal hypertensive polyps is a remarkable increase of capillary vessels in the surface of the polyp [10]. In this case, the polyps were located in the greater curvature and showed a remarkable increase of capillary vessels in the surface of the hyperplastic polyps that corresponded to those of portal hypertensive polyps.

In this case, the gastric polyps developed from non-atrophic mucosa without HP infection and disappeared completely after the discontinuation of PPI and the use of rebamipide. In general, gastric hyperplastic polyps arise from the atrophic gastric mucosa with inflammation induced by HP infection or autoimmune gastritis $[1,2]$. Recently, several reports have demonstrated the development of gastric hyperplastic polyps as well as fundic gland polyps in patients with long-term PPI use [5]. The polyps are suspected to be associated to 


\section{Case Reports in Gastroenterology}

\begin{tabular}{l|l}
\hline Case Rep Gastroenterol 2021;15:202-209 \\
\hline DOI: 10.1159/000511885 & $\begin{array}{l}\text { @ 2021 The Author(s). Published by S. Karger AG, Basel } \\
\text { www.karger.com/crg }\end{array}$ \\
\hline
\end{tabular}

Yasugi et al.: Disappearance of Gastric Hyperplastic Polyps after the Discontinuation of Proton Pump Inhibitor in a Patient with Liver Cirrhosis

hypergastrinemia induced by the prolonged use of PPI $[3,12,13]$. In our case, HP infection was negative, and the endoscopy found no hypergastrinemia-related gastric mucosa atrophy (776 pg/dL). Our previous studies about the pathogenesis of gastric hyperplastic and other types of polyps demonstrated that hypergastrinemia induced by severe atrophic gastritis of the corpus or the prolonged use of PPI might play a role in the development of gastric hyperplastic polyps [14]. It is well known that gastrin has a trophic effect on gastrointestinal mucosa [12]. The rebamipide was used to decrease the gastrin level in the blood as well as to assist in repairing the gastric mucosal tissue [15].

It is well known that the disappearance or regression of fundic gland polyps is found in patients after the discontinuation of prolonged PPI use [13]. Moreover, two reports from Japan have demonstrated a similar phenomenon in patients with gastric hyperplastic polyps caused by PPI [7, 8]. Okazaki et al. [7] reported that gastric hyperplastic polyps disappeared 1 year after switching from PPI to an $\mathrm{H} 2$ receptor antagonist in an HP-negative patient with GERD. While the serum gastrin level was not indicated, Anjiki et al. [8] also reported on an HPpositive case of multiple hyperplastic polyps with adenocarcinoma. In that case, hypergastrinemia induced by PPI was found and after discontinuing PPI, the gastric polyps disappeared with the normalization of gastrin level. HP eradication therapy was also performed after discontinuing PPI. It is well known that HP eradication therapy normalizes serum gastrin levels which allows gastric hyperplastic polyps to disappear. Therefore, it is difficult to conclude whether the eradication of HP or the discontinuation of PPI might be responsible for the disappearance of gastric polyps.

In general practice, PPI is commonly used for long periods of time as therapy for reflux esophagitis, peptic ulcer diseases and their prevention, and HP eradication therapy. If gastric hyperplastic polyps with complications, such as bleeding or anemia are observed, as they were in this case, it is necessary to consider whether hypergastrinemia is being caused by PPI, and to decide to decrease the dose of PPI, switch to an $\mathrm{H} 2$ receptor antagonist, or discontinue the PPI altogether.

\section{Acknowledgements}

We would like to thank Ayumi Iwata for revising this article, including English expressions.

\section{Statement of Ethics}

We have reported this case in compliance with the Declaration of Helsinki. Written informed consent was obtained from the patient and her next of kin for publication of this case report and any accompanying images.

\section{Conflict of Interest Statement}

The authors have no conflicts of interest to declare.

\section{Karger'"}




\section{Case Reports in Gastroenterology}

\section{Funding Sources}

No authors have declared any specific grant for this article.

\section{References}

1 Abraham SC, Singh VK, Yardley JH, Wu TT. Hyperplastic polyps of the stomach: associations with histologic patterns of gastritis and gastric atrophy. Am J Surg Pathol. 2001 Apr;25(4):500-7.

2 Yamanaka K, Miyatani H, Yoshida Y, Ishii T, Asabe S, Takada O, et al. Malignant transformation of a gastric hyperplastic polyp in a context of Helicobacter pylori-negative autoimmune gastritis: a case report. BMC Gastroenterol. 2016 Oct;16(1):130.

3 Hongo M, Fujimoto K; Gastric Polyps Study Group. Incidence and risk factor of fundic gland polyp and hyperplastic polyp in long-term proton pump inhibitor therapy: a prospective study in Japan. J Gastroenterol. 2010 Jun;45(6):618-24.

4 Zelter A, Fernández JL, Bilder C, Rodríguez P, Wonaga A, Dorado F, et al. Fundic gland polyps and association with proton pump inhibitor intake: a prospective study in 1,780 endoscopies. Dig Dis Sci. 2011 Jun;56(6):1743-8.

5 Miyamoto S, Kato M, Matsuda K, Abiko S, Tsuda M, Mizushima T, et al. Gastric hyperplastic polyps associated with proton pump inhibitor use in a case without a history of Helicobacter pylori infection. Intern Med. 2017;56(14):1825-9.

6 Stockbrügger RW, Menon GG, Beilby JO, Mason RR, Cotton PB. Gastroscopic screening in 80 patients with pernicious anaemia. Gut. 1983 Dec;24(12):1141-7.

7 Okazaki Y, Kotani K, Higashi Y. Vanishing gastric hyperplastic polyps. BMJ Case Rep. 2019;12e231341. https://doi.org/10.1136/bcr-2019-231341.

8 Anjiki H, Mukaisho KI, Kadomoto Y, Doi H, Yoshikawa K, Nakayama T, et al. Adenocarcinoma arising in multiple hyperplastic polyps in a patient with Helicobacter pylori infection and hypergastrinemia during long-term proton pump inhibitor therapy. Clin J Gastroenterol. 2017 Apr;10(2):128-36.

9 Ji F, Wang ZW, Ning JW, Wang QY, Chen JY, Li YM. Effect of drug treatment on hyperplastic gastric polyps infected with Helicobacter pylori: a randomized, controlled trial. World J Gastroenterol. 2006 Mar;12(11):1770-3.

10 Amarapurkar AD, Amarapurkar D, Choksi M, Bhatt N, Amarapurkar P. Portal hypertensive polyps: distinct entity. Indian J Gastroenterol. 2013 May;32(3):195-9.

11 Kara D, Hüsing-Kabar A, Schmidt H, Grünewald I, Chandhok G, Maschmeier M, et al. Portal hypertensive polyposis in advanced liver cirrhosis: the unknown entity? Can J Gastroenterol Hepatol. 2018 Aug;2018:2182784.

12 Haruma K, Kamada T, Manabe N, Suehiro M, Kawamoto H, Shiotani A. Old and new gut hormone, gastrin and acid suppressive therapy. Digestion. 2018;97(4):340-4.

13 Tanaka M, Kataoka H, Yagi T. Proton-pump inhibitor-induced fundic gland polyps with hematemesis. Clin J Gastroenterol. 2019 Apr;12(2):193-5.

14 Haruma K, Yoshihara M, Sumii K, Tari A, Watanabe C, Kodoi A, et al. Gastric acid secretion, serum pepsinogen I, and serum gastrin in Japanese with gastric hyperplastic polyps or polypoid-type early gastric carcinoma. Scand J Gastroenterol. 1993 Jul;28(7):633-7.

15 Haruma K, Ito M. Review article: clinical significance of mucosal-protective agents: acid, inflammation, carcinogenesis and rebamipide. Aliment Pharmacol Ther. 2003 Jul;18 Suppl 1:153-9. 


\section{Case Reports in Gastroenterology}
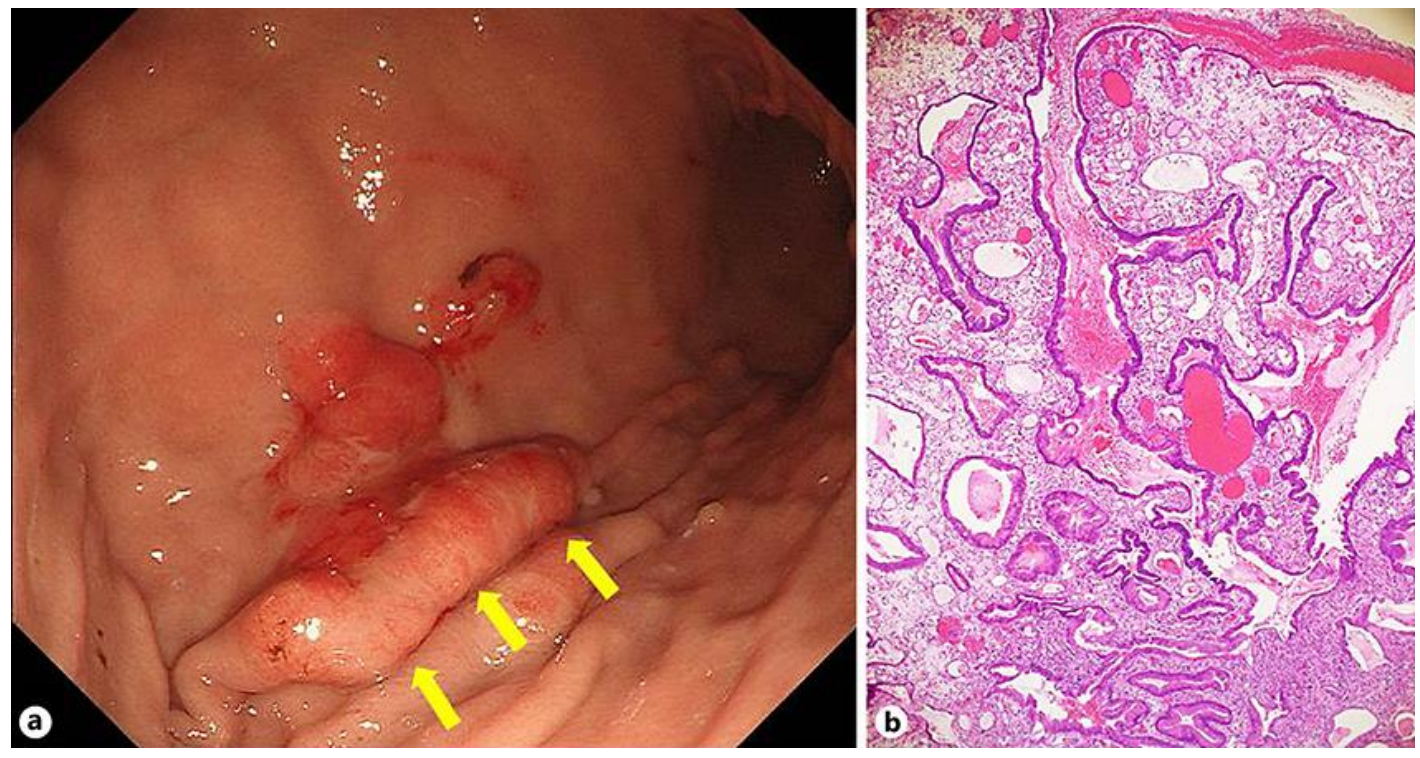

Fig. 1. A part of the mucosal folds of the greater curvature of the stomach was swollen like a sausage, with a red surface (arrows). A red ridge on the fold beside the main lesion was also recognized. Two consecutive raised lesions on the fold beside the main lesion were also recognized. In addition, a broad-based reddish polypoid lesion was observed on the anterior wall side next to the two lesions, with a clot adhering to part of it. In addition, two small fundic gland polyps were noted (a). Biopsy specimens of gastric polyps show hyperplasia of the foveolar epithelium cells with edema of lamina propria and an increase of capillaries (H\&E stain, $\times 100)(b)$. 


\section{Case Reports in Gastroenterology}
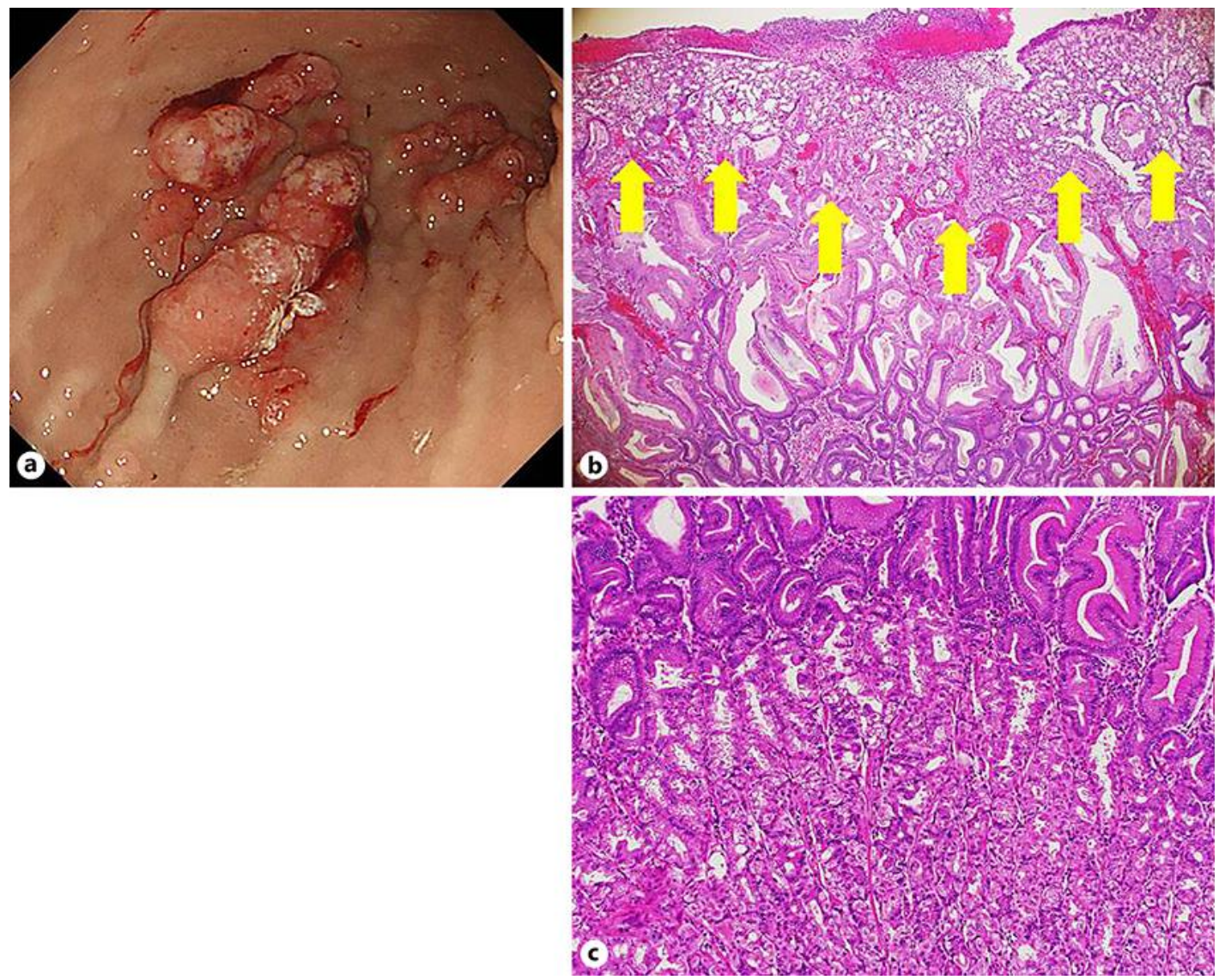

Fig. 2. Compared with the previous findings, the morphology of the polypoid lesions has obviously changed. The swelling has increased, the number of lesions has also increased, and there are white mossy surface nodules with clots attached. Additionally, ridged lesions were found on the pylorus side in line with the mucosal folds (a). Pathological findings of the resected polyps showed the crypt hyperplasia with an edematous lamina propria containing prominent ectasia in the vessels of the surface epithelium (arrows) (H\&E stain, $\times 200$ ) (b). The deep layer of the resected polyps shows cystic dilation of the fundic glands and a remarkable hyperplasia of the parietal cells $(H \& E$ stain, $\times 400)(c)$.

\section{Karger'}




\section{Case Reports in Gastroenterology}
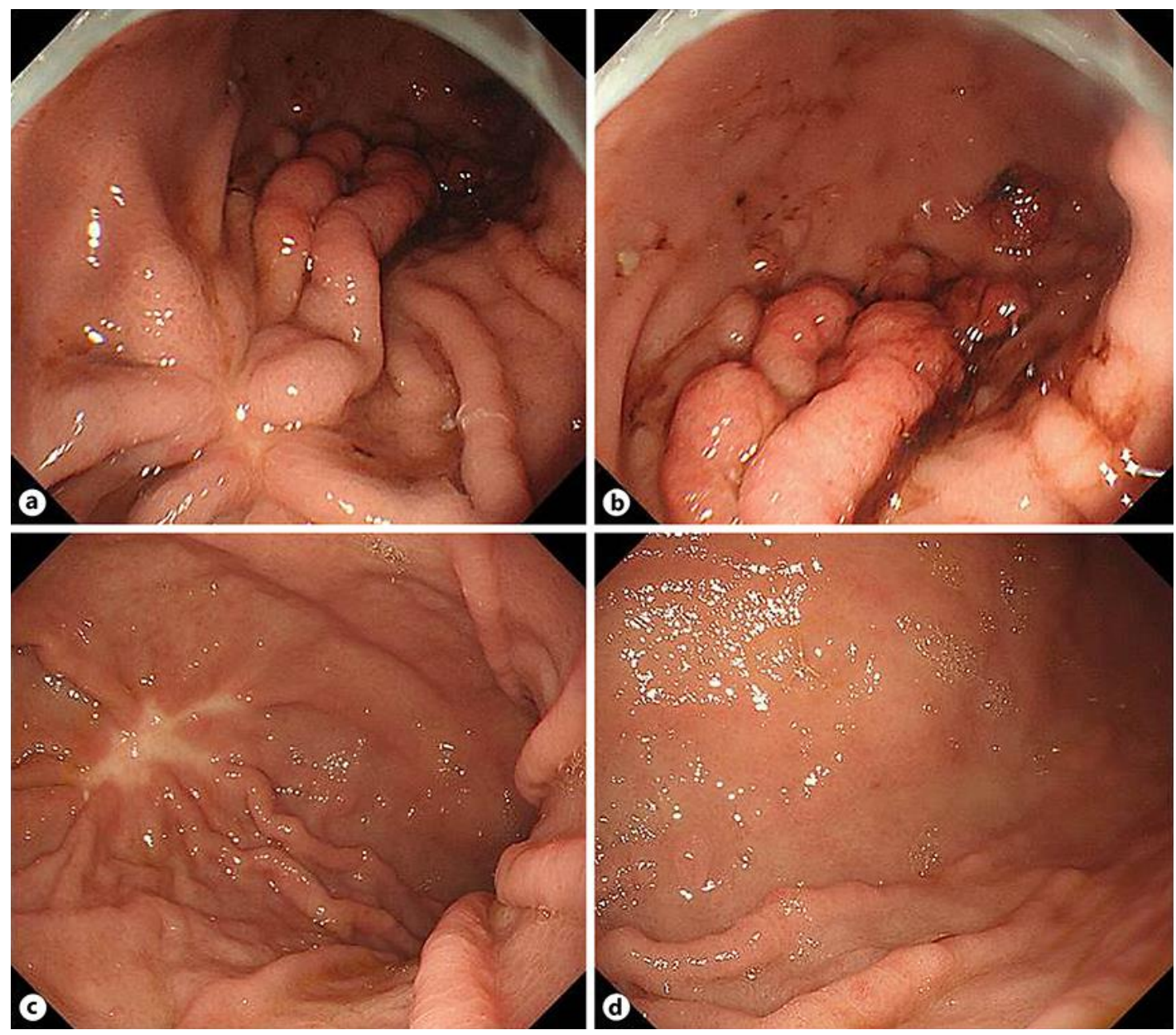

Fig. 3. The area resected by EMR scarred and no ridge formation was observed (a). However, the ridge on the fold side on the pylorus side increased, and there were many raised lesions with blood clots on the pylorus side (b). Endoscopic findings 1 year and 6 months after the discontinuation of PPI and with the use of rebamipide are shown. Although post-EMR scarring with conversing folds is found in the middle of corpus (c), the welling of mucosal folds and surface redness are not found. All previous polypoid lesions in the antrum completely disappeared (d). 